\title{
INCITACIÓN AL TERRORISMO Y LIBERTAD DE EXPRESIÓN: EL MARCO INTERNACIONAL DE UNA RELACIÓN PROBLEMÁTICA
}

GÖRAN ROLLNERT LIERN 
SUMARIO

I. PLANTEAMIENTO DE LA CUESTIÓN. LA INDEFINICIÓN DE LA INCITACIÓN AL TERRORISMO EN EL SISTEMA DE NACIONES UNIDAS. II. LA PROVOCACIÓN PÚBLICA AL TERRORISMO EN EL CONVENIO NÚM. 196 DEL CONSEJO DE EUROPA: LA DELIBERADA INCLUSIÓN DE LA INCITACIÓN INDIRECTA. III. LA JURISPRUDENCIA DEL TRIBUNAL DE ESTRASBURGO COMO PARÁMETRO INTERPRETATIVO DEL CONVENIO. IV. LAS CRÍTICAS AL MODELO EUROPEO DE PENALIZACIÓN DE LA INCITACIÓN AL TERRORISMO. V. LOS DESARROLLOS JURISPRUDENCIALES POSTERIORES DEL TEDH. LOS CASOS LEROY Y YAVUZ Y YAYALI. VI. EL ENFOQUE NORTEAMERICANO: INMINENCIA Y PROBABILIDAD. VII. CONCLUSIONES. 


\title{
INCITACIÓN AL TERRORISMO Y LIBERTAD DE EXPRESIÓN: EL MARCO INTERNACIONAL DE UNA RELACIÓN PROBLEMÁTICA*
}

\author{
GÖRAN ROLLNERT LIERN \\ Profesor Titular de Derecho Constitucional \\ Universidad de Valencia
}

\section{PLANTEAMIENTO DE LA CUESTIÓN. LA INDEFINICIÓN DE LA INCITACIÓN AL TERRORISMO EN EL SISTEMA DE NACIONES UNIDAS}

La penalización de la incitación al terrorismo representa el punto crítico en el que la lucha contra el fenómeno terrorista puede justificar restringir la libertad de expresión de la forma más invasiva y contundente, esto es, criminalizando manifestaciones y expresiones que, si se produjeran en un contexto distinto, en principio, podrían gozar de la protección dispensada al ejercicio legítimo de un derecho fundamental.

El reconocimiento del derecho a la libertad de expresión en los instrumentos internacionales ha ido siempre acompañado de su consideración como un derecho limitable en atención a la protección de bienes sobre los que indubitadamente repercute de forma directa la actividad terrorista ${ }^{1}$. Pero el problema que plantea la tipificación penal de la incitación al terrorismo en las legislaciones nacionales no es la legitimidad de los fines que pueden avalar en abstracto la necesidad de una respuesta penal, sino la configuración legislativa de las circunstancias concretas cuya presen-

* La versión final del presente trabajo es resultado de una estancia de investigación en el Departamento de Estudios Jurídicos «Angelo Sraffa» de la Università Commerciale Luigi Bocconi de Milán realizada en junio-julio de 2014. El autor agradece a la prof. ${ }^{a}$ Arianna Vedaschi sus valiosas e incisivas sugerencias y orientaciones.

${ }^{1}$ Arts. 29.2 DUDH, 19.2 PIDCP y 10.2 CEDH. 
cia puede, de conformidad con los estándares internacionales, justificar la persecución criminal de los discursos justificadores y exculpatorios de las prácticas terroristas. La dificultad fundamental surge cuando las expresiones utilizadas no contienen una apelación directa a la perpetración de actos terroristas sino que el efecto incitador resulta de la valoración de diversos aspectos subjetivos y objetivos y ello abre un abanico de cuestiones en relación con los elementos contextuales que deben concurrir en la conducta criminalizada como las circunstancias en las que se produzca la difusión del mensaje y el medio utilizado, la intención del emisor, la posibilidad o probabilidad de que se cometa el acto y su conexión causal con la expresión utilizada o el carácter inminente, real e inmediato del riesgo o peligro de que se produzca el acto terrorista. El análisis del tratamiento de estas cuestiones - por naturaleza conflictivas desde el momento en que reducen el ámbito de ejercicio legítimo de la libertad de expresión- en el vigente marco internacional en materia de lucha contra el terrorismo, constituye el objeto del presente trabajo.

Como punto de partida, hay que constatar que en el ámbito del sistema de las Naciones Unidas, aunque la Resolución 1373 (2001) del Consejo de Seguridad, dictada a los pocos días de los ataques del 11-S, se refirió directamente por primera vez a la incitación al terrorismo ${ }^{2}$ (al declarar que «incitar» a la comisión de actos terroristas «es contrario a los propósitos y principios de las Naciones Unidas ${ }^{3}$ ») fue, sin embargo, la Resolución 1624 (2005) del Consejo de Seguridad la que abordó frontalmente la cuestión. Así, después de condenar «en los términos más enérgicos la incitación a la comisión de actos de terrorismo», repudiar «los intentos de justificación o glorificación (apología) de actos de terrorismo que puedan incitar a la comisión de nuevos actos de terrorismo» y declarar la urgencia de afrontar internacionalmente la problemática de la incitación al terrorismo, el Consejo de Seguridad en la parte dispositiva «insta a todos los Estados a que adopten las medidas necesarias y adecuadas en cumplimiento de sus obligaciones de Derecho Internacional para: a) prohibir por ley la incitación a la comisión de un acto o actos de terrorismo ${ }^{4} »$.

2 Aunque el art. 20.2 PIDCP exige a los Estados parte prohibir por ley «toda apología del odio nacional, racial o religioso que constituya incitación a la discriminación, la hostilidad o la violencia», no todos los casos de incitación al terrorismo son susceptibles de ser subsumidos en esta disposición que, por otra, parte no impone la obligación de sancionar penalmente dichos actos. Vid. al respecto RoneN, Y. (2010). «Incitement to terrorist acts under international law». Leiden Journal of International Law, vol. 23, núm. 3, Hebrew University International Law Research Paper núm. 15-09, pp. 9-13, http://ssrn.com/abstract=1448667, recuperado el 11.04.2014.

3 S/RES/1373 (2001), de 28 de septiembre, ap. 5.

${ }^{4}$ S/RES/1624 (2005), de 21 de septiembre, ap. 1. Este llamamiento tuvo su continuidad en la Estrategia Global de las Naciones Unidas contra el terrorismo aprobada por la Asamblea General en 2006 (A/RES/60/288, de 8 de septiembre de 2006, apartado I.4 del Plan de Acción incorporado como anexo). 
Asimismo, instó a los Estados a informar de las medidas adoptadas para aplicar dicha Resolución ${ }^{5}$ al Comité contra el Terrorismo previamente constituido por la Resolución 1373 (2001).

Aunque esta Resolución es posterior en 4 meses al Convenio del Consejo de Europa para la prevención del terrorismo, dada la naturaleza regional de este último, ha sido considerada como el «impulso» que dio origen a «un movimiento global que busca limitar el discurso que apoya el terrorismo, los actos terroristas o las organizaciones terroristas ${ }^{6} »$. Sin embargo, la naturaleza meramente exhortatoria y no imperativa del verbo utilizado («calls upon all the States...») lleva a negar carácter vinculante a dicha resolución y a afirmar la inexistencia de una obligación jurídica general de proscribir la incitación al terrorismo al no estar la misma incluida en ninguno de los tratados internacionales de ámbito universal relativos al terrorismo .

\section{LA PROVOCACIÓN PÚBLICA AL TERRORISMO EN EL CONVENIO NÚM. 196 DEL CONSEJO DE EUROPA: LA DELIBERADA INCLUSIÓN DE LA INCITACIÓN INDIRECTA}

Pero si los textos de las Naciones Unidas comentados no incorporan una definición de la incitación al terrorismo, es el Convenio núm. 196 del Consejo de Europa para la prevención del terrorismo (en adelante, el Convenio), de 16 de mayo de 2005 y en vigor desde el 1 de junio de 2007, el instrumento internacional que ha venido a especificar los elementos que deben concurrir en las conductas susceptibles de ser consideradas incitación a cometer actos terroristas. Así, el art. 5 de la misma, bajo la rúbrica «provocación pública para cometer delitos terroristas» establece:

«1. A los efectos del presente Convenio, se entenderá por «provocación pública para cometer delitos terroristas» la difusión o cualquier

${ }^{5}$ Los informes de los Estados pueden consultarse en www.un.org/en/sc/ctc/resources/1624. html, recuperado el 11.03.2014.

${ }^{6}$ Barak-ERez, D. y Scharia, D. (2011). «Freedom of speech, support for terrorism, and the challenge of global constitutional law». Harvard National Security Journal, vol. 2, p. 3, http:// ssrn.com/abstract $=1735007$, recuperado el 11.03.2014.

7 Conte, A. (2010). Human rights in the prevention and punishment of terrorism, Berlin; London, Springer, pp. 59-60, 453 y 809. Se basa este autor en la opinión consultiva evacuada por el Tribunal Internacional de Justicia con relación a Namibia [Legal Consequences for States of the Continued Presence of South Africa in Namibia (South-West Africa) Notwithstanding Security Council Resolution 276 (1990) (Advisory Opinion) [1971] ICJ Reports 53] en virtud de la cual una resolución redactada en términos no prescriptivos no puede considerarse que imponga una obligación jurídica a un Estado miembro. 
otra forma de puesta a disposición del público de mensajes con la intención de incitar a cometer delitos terroristas, cuando ese comportamiento, ya preconice directamente o no la comisión de delitos terroristas, cree peligro de que se puedan cometer uno o varios delitos. 2. Cada Parte adoptará las medidas necesarias para tipificar como delito, de conformidad con su derecho interno, la provocación pública para cometer delitos terroristas tal como se define en el apartado 1, cuando se cometa ilegal e intencionadamente».

La redacción del art. 5 del Convenio es en gran medida consecuencia de los trabajos desarrollados previamente por el grupo de trabajo del Comité de Expertos sobre el Terrorismo (CODEXTER) dedicado específicamente a la apología del terrorismo. A partir del informe de 2003 de un experto independiente ${ }^{8}$, el Grupo de Trabajo CODEXTER-Apologie llegó a la conclusión de la existencia de una laguna en el Derecho Internacional con relación a la apología y/o la incitación al terrorismo 9 y, tomando también en consideración la recopilación de la jurisprudencia más relevante del TEDH realizada por el propio Comité ${ }^{10}$, presentó una propuesta preliminar de redacción de las disposiciones sobre esta materia a incluir en un posible instrumento internacional ${ }^{11}$.

Con estos antecedentes, el Informe Explicativo ${ }^{12}$ del Convenio aborda varias de las cuestiones más polémicas ${ }^{13}$ que suscita la inclusión de la provocación pública al terrorismo entre los delitos a tipificar por los Estados parte.

Así, el Informe se hace eco de la discusión mantenida en los trabajos preparatorios del CODEXTER acerca de la necesidad de «analizar cuidadosamente el riesgo potencial de una restricción de libertades fundamentales ${ }^{14} \gg$ y reconoce

${ }^{8}$ Elaborado por RibBelink, O., del T. M. C. Asser Instituut-Centre for International and European Law, de La Haya, y publicado después como CounCIL of Europe (ed.). (2004). «Apologie du terrorisme» and «incitement to terrorism». Strasbourg, Council of Europe Publishing.

9 CODEXTER (2004) 16. 2nd Meeting Report. Strasbourg, Council of Europe, p. 3. Todos los informes del CODEXTER en http://goo.gl/4m8Zls, recuperado el 11.04.2014.

${ }^{10}$ CODEXTER (2004) 19. Collection of relevant case-law of the European Court of Human Rights related to «apologie du terrorisme» and «incitement to terrorism». Strasbourg, Council of Europe, http:// goo.gl/GyqsRu, recuperado el 15.04.2014.

${ }^{11}$ CODEXTER (2004) 25. 3rd Meeting Report. Strasbourg, Council of Europe, pp. 14-15; y CODEXTER (2005) 15. 8th Meeting Report. Strasbourg, Council of Europe, pp. 2-7.

${ }_{12}$ Council of Europe Convention on the Prevention of Terrorism (CETS n.. 196). Explanatory Report, http://conventions.coe.int/Treaty/EN/Reports/Html/196.htm, recuperado el 13.03.2014.

${ }_{13} \mathrm{Al}$ respecto de las discusiones en torno a la redacción del art. 5 del Convenio, Hunt, A. (2006). «The Council of Europe Convention on the Prevention of Terrorism». European Public Law, vol. 12, núm. 4, pp. 616-623.

${ }^{14}$ Ésta y todas las citas literales subsiguientes proceden, si no se indica otra cosa, de los apartados 88 a 105 del Explanatory Report ya mencionado. 
que «la cuestión es donde se encuentra la frontera entre la incitación indirecta a cometer actos terroristas y las legítimas expresiones de crítica».

A partir de ahí afirma que el art. 5 recurre a la fórmula genérica de «provocación pública» y no a otra más casuística, con la finalidad de criminalizar la defensa pública de los delitos terroristas, siendo «irrelevante» para la aplicación del artículo que dicha defensa sea hecha «directa o indirectamente». Dado que la provocación directa no plantea problemas al ser ya un delito en la mayoría de los ordenamientos nacionales, «el objetivo de hacer de la provocación indirecta un delito es dar solución a la laguna existente en el Derecho y la acción internacionales incorporando disposiciones sobre esta materia». Se afirma, no obstante, que se permite «cierto margen de discreción» a los Estados con respecto a la definición del delito y su implementación de tal manera que, se dice, «por ejemplo, presentar un delito terrorista como necesario y justificado puede ser constitutivo del delito de incitación indirecta».

Se explica así el uso de la categoría de «provocación pública», en lugar de las expresiones más comunes de apología o incitación, para dar satisfacción a dos inquietudes distintas puestas de manifiesto durante los debates: por una parte, emplear un término que englobase todos los elementos que forman la base común a las diferentes situaciones que subyacen a las diferentes definiciones legales («apología», «incitación», «instigación ${ }^{15} »$, etc.) adoptadas por los Esta$\operatorname{dos}^{16} ; y$, por otra, superar el desacuerdo entre la delegaciones estatales contrarias a que el Convenio penalizara la incitación indirecta y las que consideraban que la exclusión de la incitación indirecta restaría al Convenio cualquier valor añadido en la medida que la incitación directa estaba ya siendo criminalizada en casi todos los sistemas jurídicos. Si bien la redacción preliminar propuesta por el CODEXTER incluía en la provocación pública tanto incitar a la comisión de actos terroristas como, alternativamente, presentarlos como «necesarios y justificados ${ }^{17} »$, la versión final del borrador y el texto del Convenio eliminaron esta última segunda variante de la provocación pública dejando a la discreción de los Estados incorporar al tipo penal concreto de su legislación nacional la conducta

15 La instigación diferiría, sin embargo, de la incitación precisamente por su carácter no público a decir de Kremnitzer, M. (2003). «Coping with Public Incitement to Violence». Palestine-Israel Journal, 10.2, p. 46.

${ }^{16}$ CODEXTER (2004) 16, cit., p. 3. Estos elementos comunes serían la expresión pública de apoyo a actos y/o grupos terroristas; nexo causal — directo o indirecto- con la perpetración de un acto terrorista; y conexión temporal —ex ante o ex post — con dicha perpetración.

17 «a «provocación pública a cometer actos de terrorismo» se define como una afirmación, accesible a una amplia audiencia, incitando a la comisión de actos de terrorismo [o presentando los actos de terrorismo como necesarios y justificados]» [CODEXTER (2004) 25, cit., p. 14 ]. 
de presentar el terrorismo como «necesario y justificado ${ }^{18}$ ", conducta ésta que viene a coincidir esencialmente con la definición operativa de la apología que se maneja en el informe independiente de $2003^{19}$.

La intención específica de incitar a la comisión de un delito de terrorismo es, según indica el Informe, la primera de las condiciones requeridas para la aplicación del tipo de provocación pública al terrorismo (párrafo 1. ${ }^{\circ}$ ) lo que se complementa con la exigencia del párrafo $2{ }^{\circ}$ de que la provocación sea cometida «ilegal e intencionadamente».

Aunque en el informe independiente sobre apología se incluían cautelas acerca de la exigencia de intencionalidad ${ }^{20}$ y la misma fue discutida durante las primeras reuniones del CODEXTER, las delegaciones estatales estuvieron de acuerdo en incluir en el texto una referencia explícita a la intencionalidad de la provocación pública $^{21}$. Comentando el texto del Convenio, la Subdivisión de Prevención del Terrorismo de la Oficina de las Naciones Unidas contra la Droga y el Delito interpreta, no obstante, que cabe una apreciación indiciaria de dicha intención subjetiva infiriéndola de circunstancias fácticas objetivas, aplicando el mismo principio probatorio que se recoge en otros instrumentos internacionales relativos a otros delitos ${ }^{22}$.

Una segunda condición, ésta de naturaleza objetiva, es que el resultado de la acción de distribución del mensaje al público «cree peligro de que se puedan cometer uno o varios delitos [de terrorismo]». El resultado requerido es, pues, la mera causación del peligro de que el delito sea cometido y no la comisión efectiva del delito; en este sentido el art. 8 del Convenio recoge el principio de irrelevancia del resultado al establecer que "para que un acto constituya delito en virtud de los artículos 5 a 7 del presente Convenio, no será necesario que el delito terrorista se haya cometido efectivamente».

18 El Comisario de Derechos Humanos del Consejo de Europa criticó la excesiva discrecionalidad que el texto propuesto dejaba a los parlamentos nacionales para definir el tipo delictivo, en perjuicio del objetivo de armonización legislativa y mejora de la cooperación internacional, así como a los tribunales internos para interpretar si existe o no incitación indirecta a la luz de las circunstancias lo que podría entrar en conflicto con el principio de legalidad penal $[\mathrm{CommDH}$ (2005) 1, Opinion of The Commissioner for Human Rights, Álvaro Gil-Robles, on the draft Convention on the prevention of terrorism. Strasbourg, aps. 27-30, http://goo.gl/yVqFD2, recuperado el 11.04.2014].

19 «Expresión pública de alabanza, apoyo o justificación de terroristas y/o actos terroristas» [Council of Europe (ed.). (2004), p. 12]. El Preámbulo de la Resolución 1624 (2005) considera apología la «justificación o glorificación» de actos de terrorismo.

${ }^{20}$ COUNCIL OF EUROPE (ed.). (2004), p. 31.

${ }^{21}$ CODEXTER (2004) 34. 4th Meeting Report. Strasbourg, Council of Europe, p. 4.

22 Oficina de las Naciones Unidas contra la Droga y el Delito, Subdivisión de Prevención Del Terrorismo (2006). Prevención de los actos terroristas: estrategia de justicia penal que incorpora las normas del Estado de Derecho en la aplicación de los instrumentos de las Naciones Unidas relativos a la lucha contra el terrorismo. Documento de trabajo sobre asistencia técnica. Nueva York, Naciones Unidas, pp. 22-23 y 12, http://goo.gl/9iuVqX, recuperado el 11.04 .2014$. 
Esta redacción del art. 5.1 fue consecuencia de una propuesta de compromiso entre los Estados contrarios a penalizar la incitación indirecta y la primera versión propuesta por el Grupo de Trabajo que incluía en el tipo de provocación pública presentar un acto de terrorismo como necesario y justificado, argumentándose que la incorporación del requisito de peligro hacía innecesaria esa referencia a la presentación de un acto de terrorismo como necesario y justificado. No obstante, en la discusión se plantearon dudas sobre «la posible necesidad de incluir un elemento de probabilidad, de riesgo significativo, de razones para creer que el delito de terrorismo sea cometido o sobre la relación entre la incitación y la comisión de un acto de terrorismo ${ }^{23} »$ y aunque finalmente se aceptó la propuesta, algunos Estados manifestaron sus reservas al texto (entre ellos, España y los observadores de Estados Unidos).

Finalmente, como parte del compromiso alcanzado ${ }^{24}$, el Informe Explicativo incorporó los criterios a tener en cuenta para la apreciación del peligro: «al considerar si se causa tal peligro, la naturaleza del autor y del destinatario del mensaje, así como el contexto en el que el delito sea cometido ${ }^{25}$, será tenida en cuenta en el sentido establecido por la jurisprudencia del Tribunal Europeo de Derechos Humanos. La importancia y la credibilidad del peligro deberían considerarse al aplicar esta disposición de conformidad con las exigencias del Derecho interno».

\section{LA JURISPRUDENCIA DEL TRIBUNAL DE ESTRASBURGO COMO PARÁMETRO INTERPRETATIVO DEL CONVENIO}

Desde las Directrices sobre derechos humanos y la lucha contra el terrorismo adoptadas por el Comité de Ministros del Consejo de Europa el 11 de julio de 2002,

${ }^{23}$ CODEXTER (2005) 5. 7th Meeting Report. Strasbourg, Council of Europe, aps. 27 y 28.

${ }^{24}$ Ibid., ap. 29. Se destacó que el Informe Explicativo debería también recoger los ejemplos dados por el Comisario de Derechos Humanos en su Opinión sobre el borrador del Convenio que propuso «especificar otras formas de conducta, tales como la difusión de mensajes alabando al autor de un atentado, la denigración de las víctimas, las llamadas a financiar organizaciones terroristas u otros comportamientos similares que podrían constituir provocación indirecta a la violencia terrorista», y así se hizo finalmente [Explanatory Report, ap. 95 y CommDH (2005) 1, ap. 30].

${ }^{25}$ Estos criterios se incluyen entre las variables que identificarían lo que se denomina el «discurso peligroso» en el contexto de la violencia masiva, definiendo tal como aquel que «tiene una razonable oportunidad de catalizar o amplificar la violencia de un grupo contra otro dadas las circunstancias en las que se ha producido o distribuido [BENESCH, S. (2013). Dangerous speech: a proposal to prevent group violence, http://goo.gl/k3IE0Z, recuperado el 11.04.2014]. 
la doctrina jurisprudencial del TEDH se ha considerado una «fuente primaria ${ }^{26}$ » para definir orientaciones de la lucha contra el terrorismo.

Los trabajos del CODEXTER preparatorios del Convenio insistieron en la misma línea ${ }^{27}$ y en 2004 dicho Comité preparó un documento con la colección de la jurisprudencia relevante del TEDH en relación con la apología y la incitación ${ }^{28}$ que sirvió de base a las discusiones sobre el borrador, llevándose finalmente al Informe Explicativo la mención expresa a dicha jurisprudencia como referente del «sentido» en que tendrían que ser interpretados los elementos a valorar para considerar si la conducta en cuestión cumple con la condición objetiva de crear "peligro de que se cometan uno o varios delitos» de terrorismo ${ }^{29}$.

Más en particular, el Informe Explicativo asume literalmente la opinión del Comisario de Derechos Humanos que recurrió a una decisión de inadmisibilidad del TEDH en concreto (Hogefeld c. Alemania, de 20 de enero de 2000) para argumentar que, al igual que el odio racial no puede ser considerado admisible con el argumento de la libertad de expresión, lo mismo es aplicable a la incitación a delitos terroristas violentos, fundándose en que «el Tribunal ya ha mantenido que ciertas restricciones a mensajes que pueden constituir una incitación indirecta a delitos terroristas violentos son conformes con el Convenio [Europeo de Derechos Humanos $]^{30} »$.

Atendiendo a este documento recopilatorio de jurisprudencia manejado por el Comité $^{31}$, pueden destacarse los siguientes criterios interpretativos principales ${ }^{32}$ :

${ }^{26}$ Guidelines on human rights and the fight against terrorism, as adopted by the Committee of Ministers of the Council of Europe on 11 July 2002, Texts of reference. Strasbourg, Council of Europe, p. 16, http://goo.gl/Iffga2, recuperado el 11.04.2014.

27 Council of Europe (ed.). (2004), p. 31; CODEXTER (2004) 25, p. 3; y CODEXTER (2004) 34, p. 4.

28 CODEXTER (2004) 19.

29 Explanatory Report, ap. 100.

30 CommDH (2005) 1, ap. 26; y Explanatory Report, ap. 91. El último apartado del Informe Explicativo sobre la provocación pública al terrorismo termina remitiendo al lector a la jurisprudencia del TEDH para «mayor orientación» (ap. 105).

31 A los efectos del presente artículo se trata de analizar la interpretación de la doctrina jurisprudencial del TEDH que se utilizó en los trabajos preparatorios del Convenio para configurar normativamente el delito de provocación pública al terrorismo, sin perjuicio de que se haya acudido directamente al texto íntegro de las decisiones. El estudio detallado de la doctrina jurisprudencial del TEDH sobre la incitación al terrorismo daría lugar a otro trabajo diferente que el que ahora se presenta al lector; puede verse al respecto el apartado dedicado a la libertad de expresión de SALINAS DE Frías, A. (2012). Counter-terrorism, and human rights in the case-law of the European Court of Human Rights. Strasbourg, Council of Europe Publishing, pp. 133-144. Una crítica a dicha doctrina desde la perspectiva norteamericana en Boyne, S. M. (2010). «Free Speech, Terrorism, and European Security: Defining and Defending the Political Community». Pace Law Review, vol. 30, pp. 440-446 y 468-480.

32 Para agilizar la lectura se prescinde de referencias a las sentencias concretas, salvo casos muy significativos. En el documento citado [CODEXTER (2004) 19], el lector puede encontrar dichas refe- 
a) «El criterio decisivo en la valoración del TEDH es si la afirmación incita a la violencia o comunica que la violencia es una medida necesaria y justificada [...]. Si es éste el caso, las penas se consideran como «una necesidad social imperiosa»y, por tanto, están justificadas de conformidad con el art. 10.2 $\mathrm{CEDH}^{33}$ », presentándose como «una cuestión de principios».

Pero este criterio decisivo se ve modulado de forma determinante por un criterio secundario cualificado, el «contexto» en el que se realiza la afirmación: «en el caso de que una declaración incriminatoria coincida con ataques o actos de violencia, es más probable que sea considerado como una incitación directa o una justificación de estos actos ${ }^{34} »$. Se equiparan, por tanto, la incitación directa a la violencia y la incitación indirecta que puede producirse cuando la justificación del recurso a la violencia es coetánea a una situación de inseguridad, disturbios o ataques, mediante la identificación con una organización violenta o bien con una incitación al odio que favorezca el recurso a la violencia al presentarla como una medida de autodefensa necesaria y justificada.

Un segundo criterio secundario permite también considerar proporcionadas restricciones a afirmaciones que «por sí solas no necesariamente tienen que ser entendidas como una incitación a actividades terroristas»: a la luz de la «historia personal» del recurrente (uno de los principales representantes de una organización terrorista responsable de múltiples atentados mortales), sus palabras «podrían posiblemente ser entendidas por sus partidarios como una llamada a continuar las actividades» de la organización terrorista ${ }^{35} »$.

b) Pero la consideración de unas manifestaciones como incitación indirecta también puede venir determinada por «el efecto nocivo sobre la prevención del desorden y el crimen», que se convierte en el criterio decisivo en caso de duda: «si el TEDH no está convencido de que las afirmaciones enjuiciadas, aunque den apoyo moral a movimientos terroristas ${ }^{36}$, puedan tener algún «efecto nocivo

rencias así como resúmenes de los hechos enjuiciados (pp. 7-15). La sistematización de dichos criterios en principales y secundarios es, sin embargo, la que le ha sugerido al autor la combinación de la lectura de dicha colección jurisprudencial con la consulta directa de las resoluciones incluidas en la misma.

${ }^{33}$ CODEXTER (2004) 19, p. 7.

34 Ibid., p. 6.

${ }^{35}$ Explanatory Report, ap. 91. La decisión de inadmisibilidad en la que se contiene este pronunciamiento concreto (Hogefeld c. Alemania, de 20 de enero de 2000) es la que, como se ha dicho, cita el Informe Explicativo del Convenio para afirmar que «el Tribunal ya ha mantenido que ciertas restricciones a mensajes que pueden constituir una incitación indirecta a delitos terroristas violentos son conformes con el CEDH».

36 Cabe destacar que, acudiendo a la sentencia, el TEDH no habla de «apoyo moral» al terrorismo en sí sino de «apoyo moral a la ideología» del líder terrorista biografiado por el condenado (caso Öztürk contra Turquía, de 28 septiembre de 1999, ap. 65). 
sobre la prevención del desorden o el crimen» [...], entonces las afirmaciones quedan bajo el ámbito de protección del art. 10 del $\mathrm{CEDH}$ ». La libertad de expresión del art. $10 \mathrm{CEDH}$ protegería por tanto el apoyo moral al terrorismo cuando el mismo sea inocuo para el orden público u otros de los objetivos legítimos previstos en el art. 10.2.

c) En contraste con la incitación directa o indirecta a la violencia, «las afirmaciones que son solamente hostiles en el tono, contienen propaganda separatista [...], crítica virulenta a la acción gubernamental o condena de la democracia mientras se preconiza la sharia islámica [...], pero no incitan a la violencia $[\ldots .$.$] , son legítimas al amparo del art. 10 \mathrm{CEDH».} \mathrm{Sin} \mathrm{embargo,} \mathrm{el}$ documento menciona el caso Refah en el que se consideró justificada la disolución de un partido político que preconizaba a largo plazo el establecimiento de un régimen basado en la sharia "porque este partido no excluyó explícitamente el recurso a la fuerza para implantar esta política ${ }^{37} »$; en este caso, el carácter «más tangible y más inmediato» del peligro que suponía para la democracia que el partido tuviera oportunidades reales de poner en práctica su política determinó que se considerase que la disolución respondía a una necesidad social imperiosa y que se concediera relevancia al hecho puramente negativo de que el partido no hubiese excluido explícitamente el recurso a la fuerza ${ }^{38}$.

d) Un cuarto criterio principal es el que se refiere a la «severidad de las medidas adoptadas» del tal manera que este puede ser el elemento determinante de que la restricción sobre la libertad de expresión pueda considerarse desproporcionada a los fines legítimos de la prevención del crimen y del desorden y no justificada en una sociedad democrática.

Junto a estos criterios principales cuya apreciación viene, a su vez, condicionada [en los criterios a y c)] por la presencia de los criterios secundarios indicados, el documento recopilatorio del CODEXTER expresa también otros criterios secundarios ${ }^{39}$ a tener en cuenta en la valoración de los hechos concretos del caso si bien con una incidencia más difusa sobre la aplicación de los criterios principales y en cuya consideración no se entra por motivos de espacio.

37 CODEXTER (2004) 19, p. 7.

38 Sobre esta sentencia, Rollnert Liern, G. (2002). La libertad ideológica en la jurisprudencia del Tribunal Constitucional (1980-2001), Madrid, Centro de Estudios Políticos y Constitucionales, pp. 211-215.

39 CODEXTER (2004) 19, pp. 6-15. 


\section{LAS CRÍTICAS AL MODELO EUROPEO DE PENALIZACIÓN DE LA INCITACIÓN AL TERRORISMO}

La definición de la provocación pública al terrorismo asumida en el Convenio ha sido también incorporada a la legislación de la Unión Europea desde que en 2008 se aprobó una enmienda de la Decisión Marco del Consejo de la Unión, de 13 de junio de 2002, sobre la lucha contra el terrorismo (2002/475/JAI). Si la Decisión Marco de 2002 se limitaba, a los efectos que nos ocupan, a establecer la obligación de todos los Estados miembros de «adoptar las medidas necesarias para tipificar como delito la inducción [...] para cometer un delito» de terrorismo (art. 4.1), la nueva Decisión Marco del Consejo, de 28 de noviembre de 2008 (2008/919/JAI) ${ }^{40}$, modificó la Decisión Marco de 2002 adoptando los mismos términos que el art. 5 del Convenio del Consejo de Europa de 2005 en la definición de la provocación pública para cometer delitos de terrorismo (art. 1.1 ${ }^{41}$ ).

La coincidencia esencial entre el Convenio del Consejo de Europa y la Decisión Marco de la Unión Europea permite hablar de un modelo europeo común de tratamiento legislativo penal de la incitación al terrorismo, sin perjuicio de la variada tipificación concreta de esta conducta en las legislaciones nacionales, de tal manera que una buena parte de las críticas y objeciones formuladas a las regulaciones del Convenio y la Decisión Marco son aplicables a ese enfoque común de la problemática de la incitación.

Un primer reproche que se hace a este modelo europeo es que parte de una definición abierta y general de la incitación al terrorismo que sería contraria al principio de seguridad jurídica. Desde los trabajos preparatorios del Convenio se puso de manifiesto la preocupación porque una descripción del

${ }^{40}$ Para un análisis crítico de este instrumento normativo desde el punto de vista de su efectividad para combatir la proliferación del radicalismo islamista en Internet, MeLLINGER, L. (20092010). «Illusion of Security: Why the Amended EU Framework Decision Criminalizing Incitement to Terrorism on the Internet Fails to Defend Europe from Terrorism». Syracuse Journal of International Law and Commerce, pp. 351-368.

41 El art. 1.1 de la nueva Decisión Marco de 2008 modifica el art. 3.1 de la Decisión Marco de 2002 en el siguiente sentido: «a efectos de la presente Decisión Marco, se entenderá por a) «provocación a la comisión de un delito de terrorismo» la distribución o difusión pública, por cualquier medio, de mensajes destinados a inducir a la comisión de cualesquiera de los delitos enumerados en el artículo 1, apartado 1, letras a) a h), cuando dicha conducta, independientemente de que promueva o no directamente la comisión de delitos de terrorismo, conlleve el riesgo de comisión de uno o algunos de dichos delitos». Aunque en las traducciones oficiales al español de ambos textos pueden observarse algunas diferencias terminológicas, la redacción es idéntica en la versión inglesa con la salvedad de que en la Decisión Marco la provocación se refiere a unos delitos de terrorismo relacionados en la misma norma [art. $1.1 \mathrm{a}$ )-h)]. 
delito de provocación pública al terrorismo que incluyera la incitación indirecta fuese suficientemente precisa para cumplir con las exigencias de claridad y certeza inherentes a los principios de legalidad penal y seguridad jurídica ${ }^{42}$.

Específicamente, la posible penalización por las legislaciones nacionales de la apología del terrorismo al amparo de la generalidad, amplitud y apertura de los términos del art. 5 del Convenio ${ }^{43}$ y de la nueva redacción del art. 3.1 de la Decisión Marco de 2002 es lo que suscitó mayores cautelas por la vaguedad de la conducta típica, no solo en el ámbito europeo ${ }^{44}$ sino en otros foros internacionales ${ }^{45}$ y académicos. Así, se ha afirmado que «los delitos que van más allá de la provocación

42 Doc. 10423, report of the Committee on Legal Affairs and Human Rights of the Parliamentary Assembly of Council of Europe, ap. 8, http://goo.gl/EHdNCH; y Parliamentary Assembly Opinion $n{ }^{\circ} 255$ (2005). Draft Convention on the Prevention of Terrorism, ap. 3, http://goo.gl/7z4f4C, recuperado el 11.04.2014. En el mismo sentido, el Comisario de Derechos Humanos del Consejo de Europa [CommDH (2005) 1, aps. 28-30].

43 Vid. infra el apartado III; y el Explanatory Report, ap. 98.

${ }^{44}$ En el seno de la propia Asamblea Parlamentaria del Consejo de Europa, el ponente del Comité de Asuntos Jurídicos y Derechos Humanos distinguió entre incitación y apología y se mostró contrario a que el Convenio obligase a los Estados a adoptar medidas contra la apología del terrorismo (Doc. 10423, ap. 22). También el Parlamento Europeo aprobó la Resolución Legislativa, de 23 de septiembre de 2008 [COM(2007)0650-C6-0466/2007-2007/0236(CNS)] proponiendo sustituir en la propuesta de Decisión Marco de 2008 el término «public provocation» por «public incitement» (enmienda núm. 12 en la versión inglesa, http://goo.gl/6J0BWL e informe de la ponente, http://goo.gl/vFjODT, recuperados el 15.04.2014; en la versión española ambos términos han sido traducidos por «inducción pública», http://goo.gl/7PHrmf, recuperado el 15.04.2014), no siendo aceptada finalmente dicha enmienda.

45 Así, el Relator Especial de las Naciones Unidas sobre la promoción y protección de los derechos humanos y las libertades fundamentales en la lucha contra el terrorismo destacó la tendencia a ir más allá de la mera incitación y tipificar como delito la «glorificación» o «apología» del terrorismo [E/CN.4/2006/98, 28 de diciembre de 2005, ap. 56 c), http://goo.gl/ $\mathrm{fVtLcK}$, recuperado el 15.04.2014] lo que, a su juicio, «no permite a los individuos regular su conducta apropiadamente» [A/61/267, ap. 7 a), http://goo.gl/9jzkZU, recuperado el 15.04.2014] y puede llevar a una limitación desproporcionada de la libertad de expresión. En el mismo sentido, la Declaración Conjunta del Relator Especial de las Naciones Unidas para la Libertad de Opinión y Expresión, el Representante de la OSCE para la Libertad de los Medios de Comunicación y el Relator Especial de la OEA para la Libertad de Expresión, expresaron su consternación porque «el estándar para restringir la expresión en supuestos de incitación, correctamente establecido en las áreas del orden público y la seguridad nacional, ha evolucionado en favor de términos vagos y potencialmente muy abarcativos (sic)» y afirmaron que, «mientras que puede ser legítimo prohibir la incitación al terrorismo o a actos de terrorismo los Estados no deben emplear términos vagos tales como «glorificando» o «promoviendo» el terrorismo cuando restringen la libertad de expresión» (http://goo.gl/YWg83u, recuperado el 15.04.2014). 
directa o la incitación para criminalizar conductas en términos tales como «glorificación»o «promoción» del terrorismo son vagos, están abiertos al abuso y probablemente vulneran el derecho a la libertad de expresión ${ }^{46}{ }_{»}$.

El posible conflicto de la definición de la provocación pública al terrorismo con el principio de legalidad es, a juicio de la Comisión Internacional de Juristas (CIJ), todavía mayor en la Decisión Marco de 2008 cuya definición tiene «un potencial mucho más amplio de aplicación» que la del Convenio por cuanto, pese a la identidad de sus términos, a diferencia del Convenio que define el delito terrorista por remisión a once tratados relativos al terrorismo que criminalizan actos específicos (art. 1.1 en relación con el Apéndice), la definición de la Decisión Marco es más general e incierta al basarse en un listado de actos más extenso que incluye también la destrucción de propiedad, infraestructuras o sistemas de información y las perturbaciones o interrupciones en el suministro de servicios esenciales, esto es, formas delictivas relacionadas con el terrorismo que van más allá del ámbito del Convenio y que pueden incluir actos de protesta y disidencia legítima, de tal forma que las legislaciones nacionales podrían ampararse en esta definición «para justificar medidas que criminalizan la provocación de actos de relativamente baja intensidad con la consecuencia de una interferencia injustificada en la libertad de expresión ${ }^{47}{ }$. La conclusión a la que llega la Comisión Internacional de Juristas es que la extensa definición del terrorismo en la Decisión Marco hará el delito de provocación al terrorismo «inaceptablemente amplio e indeterminado» y propone restringirlo a la provocación de «actos de violencia que amenacen la vida o la integridad de las personas ${ }^{48}{ }$.

Un segundo elemento problemático tiene que ver con el requisito objetivo de que la conducta de difusión del mensaje incitativo produzca un «peligro» de comisión de delitos de terrorismo. La imprecisión del carácter de dicho peligro pugna — se viene a decir — con los requisitos de necesidad y proporcionalidad que deben reunir las restricciones a la libertad de expresión en virtud de los estándares de los arts. 19.3 PIDCP y 10.2 CEDH. Para la Comisión Internacional de Juristas, la definición de la Decisión Marco tras la modificación de 2008 (y, por los mismos motivos, la definición del Convenio) deja «alguna duda sobre el nivel y la inmi-

46 Alegre, S. (2008). Human Rights concerns relevant to legislating on provocation or incitement to terrorism and related offences. Briefing paper. Brussels, European Parliament, p. 3, http://goo.gl/ GVyld4, recuperado el 15.04.2014.

47 En el mismo sentido, Mariner, J. (2008), http://goo.gl/V6gfVt, recuperado el 15.04.2014; Alegre, S. (2008), p. 2; y Boyne, S. M. (2010), pp. 449-452

48 International Commission of Jurists (2008). Briefing paper: Amendment to the Framework Decision on Combating Terrorism - Provocation to Commit a Terrorist Offence, pp. 3-5, http:// goo.gl/VNfYC, recuperado el 15.04.2014. 
nencia del riesgo necesario para que el delito de provocación sea cometido» y «permite la criminalización de discursos que no conllevan un riesgo inmediato de un acto terrorista sino tan solo una posibilidad remota» lo que supone una injerencia probablemente innecesaria y desproporcionada en la libertad de expresión.

Ciertamente, el tenor literal de la descripción normativa de la conducta típica no califica la proximidad temporal que debe existir entre el peligro de acto terrorista y la difusión del mensaje y, sobre todo, la relación entre la provocación y el acto terrorista no se configura en términos de probabilidad sino de mera posibilidad («peligro de que se puedan cometer...»), matiz terminológico que no ha pasado inadvertido y que ha sido calificado de «erosión» en el estándar de la incitación ${ }^{49}$.

Las posiciones críticas con esta concepción de un «peligro» indefinido y abstracto de posible comisión de un delito de terrorismo como presupuesto del delito de provocación pública coinciden en acudir a los Principios de Johannesburgo sobre la Seguridad Nacional, la Libertad de Expresión y el Acceso a la Información como canon interpretativo que exigiría el carácter inminente y probable del peligro en cuestión. Se invoca al respecto el Principio núm. 6 en virtud del cual «la expresión se podrá castigar como una amenaza a la seguridad nacional solo si el Gobierno puede demostrar que: (a) la expresión tiene la finalidad de incitar violencia inminente; (b) bien pudiera dar lugar a tal violencia; y (c) existe una conexión directa e inmediata entre la expresión y la probabilidad o el acontecimiento de tal violencia ${ }^{50}{ }_{»}$.

Sobre la base de este parámetro se ha apuntado que una interpretación de la provocación pública tipificada en el Convenio y la Decisión Marco que permita penalizar actos de incitación que no provoquen un riesgo de violencia inminente ${ }^{51}$

49 MARiner, J. (2008).

50 Artículo 19 (1996, ed. española de 2005). Los Principios de Johannesburgo sobre la Seguridad Nacional, la Libertad de Expresión y el Acceso a la Información. Londres, http://goo.gl/qEifdd, recuperado el 15.04.2014. Estos Principios, aprobados el 1 de octubre de 1995 por un grupo de expertos en Derecho Internacional, seguridad nacional y derechos humanos fueron asumidos por el Relator Especial para la Libertad de Opinión y Expresión de la ONU desde 1996 (Doc. E/CN.4/1996/39, 22 de marzo de 1996) en sus informes a las sesiones de la Comisión de Derechos Humanos (hoy Consejo de Derechos Humanos) de la ONU, que desde entonces se ha referido a ellos en todas sus resoluciones anuales [BROwN, I. y KorFF, D. (2012). Digital Freedoms in International Law. Global Network Initiative, p. 48, nota 26, http://ssrn.com/abstract=2085342, recuperado el 15.04.2014]. Para la Comisión Internacional de Juristas, sin ser vinculantes, proporcionan «el estándar autorizado para delitos de incitación a actos de terrorismo» [INTERNATIONAL COMMISSION OF JURISTS (2008), p. 2].

${ }^{51}$ El requisito de la inminencia había sido, sin embargo, previamente criticado por considerar que conduce, en realidad, a nulificar la eficacia de la prohibición de la incitación pública y que 
cuya probabilidad esté directamente conectada con las expresiones proferidas, no podría encontrar una justificación legítima en la protección de la seguridad nacional de acuerdo con este Principio $6^{52}$. Por su parte, la Comisión Internacional de Juristas dictaminó que, para mejor protección de la libertad de expresión contra una injerencia desproporcionada, el término «peligro» en la enmienda a la Decisión Marco debería ser sustituido por el término «riesgo inminente» y que si la propuesta no se modificaba en este sentido, como así efectivamente sucedió, «la Decisión Marco debería ser interpretada y aplicada restrictivamente requiriendo un grado de inminencia en el peligro causado ${ }^{53} »$.

Pese a las anteriores críticas, el art. 5 del Convenio núm. 196 ha sido considerado una «buena práctica» para la aplicación de la Resolución 1624 (2005) por el Comité contra el Terrorismo del Consejo de Seguridad ${ }^{54}$ y desde el año 2005 el Relator Especial de las Naciones Unidas sobre la promoción y la protección de los derechos humanos y las libertades fundamentales en la lucha contra el terrorismo, lo ha valorado positivamente ${ }^{55}$. En 2006 afirmó que «aunque el art. 5 usa el título un tanto extraño de provocación pública para cometer un delito terrorista en lugar de incitación al terrorismo, los tres elementos del delito del art. 5 están apropiadamente limitados a: un acto de comunicación; una intención subjetiva por parte de la persona de incitar al terrorismo; y un peligro objetivo adicional de que la conducta de la persona incite al terrorismo»y entiende que esta última exigencia objetiva —el peligro- «separa la incitación al terrorismo de nociones más vagas como la apología del terrorismo»; así pues, considera que cumple con los arts. 15, 19 y 20.2 del Pacto Internacional de Derechos Civiles y Políticos, siendo «suficientemente preciso ${ }^{56} \gg$.

otorga una prioridad casi absoluta a la libertad de expresión sobre la vida humana ignorando también el efecto acumulativo de las afirmaciones incitadoras siendo éste su principal efecto [KREMNitZer, M. (2003), p. 49].

52 Alegre, S. (2008), pp. 2 y 8.

53 International Commission of Jurists (2008), p. 6.

54 Counter-Terrorism Committee Executive Directorate (s. f.). United Nations Security Council Resolution 1624 (2005). Compilation of international good practices, codes and standards, p. 3, http://goo.gl/37iJhv, recuperado el 15.04.2014.

55 Así, frente a la tendencia a ir más allá de la incitación penalizando la «glorificación» o apología del terrorismo o el «aliento indirecto», el Relator lo ha calificado como «una respuesta sensata compatible con los derechos humanos» [E/CN.4/2006/98, ap. 56 c)] y como «forma recomendada de combinar el elemento de la intención con el riesgo de que el acto terrorista se cometa» (A/61/267, ap. 28).

$56 \mathrm{~A} / \mathrm{HRC} / 4 / 26$, de 14 de diciembre de 2006, addenda 3, aps. 26 y 27, http://goo.gl/jEJr6K, recuperado el 15.04.2014. 
En su Informe de 2010 el Relator recordó que ha recomendado la definición del art. 5 del Convenio como «práctica óptima ${ }^{57}$ » y la ha incluido como una de las diez esferas de mejores prácticas en la lucha contra el terrorismo; la definición del art. 5 del Convenio «constituye el fundamento del modelo de delito propuesto en la práctica 8» si bien «el Relator Especial ha introducido una pequeña modificación en la definición para incluir la conducta que provoque un riesgo objetivo de comisión de un delito de terrorismo, independientemente de que se propugne o no «expresamente» el delito de terrorismo (con preferencia a la expresión empleada en el Convenio de propugnar «directamente» el delito)». El Informe justifica este cambio terminológico como «reacción a la sentencia del Tribunal Europeo de Derechos Humanos en la causa Leroy c. Francia» (vid. infra), de tal manera que puede cometerse el delito de provocación pública aunque solo se propugne el terrorismo «mediante el empleo de lenguaje críptico» pero esta fórmula «no reduce el requisito de probar tanto la intención subjetiva de incitar como el riesgo objetivo de que se cometa un acto terrorista». Insiste el Relator Especial en que el delito de incitación al terrorismo «deberá estar definido en la ley en un lenguaje preciso, evitando en particular el empleo de términos vagos como «apología»o «promover» el terrorismo».

\section{LOS DESARROLLOS JURISPRUDENCIALES POSTERIORES DEL TEDH. EL CASO LEROY Y LAS SENTENCIAS MÁS RECIENTES}

Con posterioridad al Convenio de 2005, el Comité de Expertos contra el Terrorismo del Consejo de Europa llevó a cabo otro estudio de la jurisprudencia del TEDH recaída entre 2004 y 2008 con relación a la incitación al terrorismo ${ }^{58}$. En ese documento, presentado como una actualización del estudio previo de 2004, se concluye, después de analizar doce casos — todos ellos contra Turquía-, que no ha habido desarrollos jurisprudenciales sustanciales desde 2004 aunque el número de casos ha crecido considerablemente; se afirma que prevalece un enfoque casuístico y que la lógica jurídica sigue siendo la misma y cabe destacar tres aspectos de estas breves conclusiones ${ }^{59}$ :

a) La importancia de examinar muy de cerca «el tenor literal de las afirmaciones y su peligro potencial» atendiendo a factores como la terminología

57 A/HRC/16/51, 22 de diciembre de 2010, ap. 30, http://goo.gl/0vQ1F9, recuperado el 15.04.2014. Las citas posteriores proceden de los aps. 29-32.

58 CODEXTER (2008a). Collection of relevant case-law of the European Court of Human Rights on incitement to terrorism (2004-2008). Strasbourg: Council of Europe, http://goo.gl/UaOb6d, recuperado el 15.04.2014.

59 Ibid., p. 23. A similares conclusiones llega Salinas DE Frías (2012), pp. 138-142. 
empleada, el medio utilizado y el estatus del autor «especialmente [...] si es probable que influya en un gran número de personas».

b) La «severidad de la condena impuesta» requiere un análisis de proporcionalidad que puede llevar a que «un discurso potencialmente problemático pueda, por ejemplo, ser considerado protegido por el art. $10 \mathrm{CEDH}$ si la sentencia dictada se juzga desproporcionada».

c) Teniendo en cuenta el art. 5 del Convenio, se remarca que «la hostilidad hacia el Estado está protegida por el art. $10 \mathrm{CEDH}$, sin perjuicio de que las restricciones de las autoridades estatales al «uso de la violencia y las llamadas a la resistencia armada, la insurrección y el discurso del odio» sean consideradas en general conformes con el art. 10.2 CEDH.

Entrando a considerar los casos analizados, el Tribunal reitera ${ }^{60}$ que «el factor esencial» es si las expresiones concretas, en sí mismas o tomadas en conjunto, «no animan a la violencia, la resistencia armada o la insurrección y no constituyen discurso del odio ${ }^{61} »$ pero añade dos elementos ${ }^{62}$ a tener en cuenta para hacer esta valoración:

a) «La clara intención de estigmatizar a la otra parte del conflicto ${ }^{63}$ » puede llevar a considerar que hay incitación a la violencia aunque sean comentarios que en otro contexto pueden aparecer como observaciones sobre hechos históricos, sociales y culturales o discursos que llamen a una solución pacífica.

b) La «glorificación de la violencia asesina», la «llamada a la guerra o al menos a la reanudación del conflicto armado», en la medida que «suscitan emociones primarias y refuerzan prejuicios ya arraigados que se han manifestado en violencia letal» en el contexto de una situación de inseguridad y serios disturbios desde hace años, transmiten el mensaje de que «el recurso a la violencia es una medida necesaria y justificada de autodefensa ${ }^{64}{ }$.

${ }^{60}$ Remitiéndose entre otras a Sürek (núm. 1) c. Turquía, de 8 de julio de 1999, ap. 62; Gerger c. Turquía, de 8 de julio de 1999, ap. 50; y Zana contra Turquía, de 25 de noviembre de 1997.

${ }^{61}$ Por todas, Kalin c. Turquía, de 10 de noviembre de 2004, ap. 31.

62 Para Salinas de Frías [(2012), pp. 139-140] estos dos elementos son los que permiten diferenciar los casos en los que las expresiones utilizadas pueden considerarse «hate speech» (cuando existe la «intención de estigmatizar a la otra parte del conflicto») o mera incitación (cuando se comunica el mensaje de que «el recurso a la violencia es una medida necesaria y justificada de autodefensa»).

${ }^{63}$ Halís Dogan c. Turquía, de 7 de febrero de 2006, ap. 35.

${ }^{64} \mathrm{Ibid}$., aps. 35-36. La glorificación de la violencia había sido ya equiparada a la incitación al odio, a la venganza, a la recriminación o a la resistencia armada en el caso Sener c. Turquía, de 18 de julio de 2000, ap. 45. 
Pero, sin duda, la referencia fundamental de la doctrina del Tribunal de Estrasburgo sobre la incitación al terrorismo es la sentencia dictada el 2 de octubre de 2008 en el caso Leroy c. Francia ${ }^{65}$ calificado por el CODEXTER como «indudablemente el desarrollo jurisprudencial más destacable» por cuanto, a diferencia de la jurisprudencia anterior dictada en casos contra Turquía, no se basa en el concepto central de la incitación al terrorismo sino, por primera vez, en el concepto de «apología del terrorismo» tal y como viene definido por la legislación francesa ${ }^{66}$.

Cabe señalar, en primer lugar, respecto a esta sentencia que en ella no se contiene una definición propia de la apología del terrorismo por cuanto el Tribunal se limita a examinar si una condena por apología del terrorismo sobre la base de la legislación interna es compatible con el CEDH no siendo su tarea dar una definición precisa de un concepto que puede ser inadecuado para otro sistema jurídico ${ }^{67}$. El concepto de apología que maneja es, por tanto, el del Derecho interno, en este caso, el del Derecho francés.

Un segundo aspecto interesante es que, ante la alegación del Gobierno francés de que la demanda es inadmisible en aplicación del artículo $17 \mathrm{CEDH}$, el Tribunal considera que este artículo no es aplicable para excluir la protección del art. $10 \mathrm{CEDH}$ por cuanto «el mensaje de fondo [...] — la destrucción del imperialismo americano- no pretende negar los derechos fundamentales y no es comparable a las declaraciones dirigidas contra los valores que sirven de base al Convenio tales como el racismo, el antisemitismo [...] o la islamofobia. [...]. De otro lado, pese a la calificación de apología de terrorismo apreciada por los tribunales internos, el Tribunal considera que el dibujo en litigio y el comentario que lo acompaña no constituyen una justificación hasta tal punto inequívoca del acto terrorista como para escapar a la protección garantizada por el artículo 10» (ap. 27). Este pronunciamiento del Tribunal lleva al CODEXTER a afirmar que, en sentido contrario, «consecuentemente el art. 17 podría ser aplicado a algunas formas de expresión que buscan sin ninguna ambigüedad justificar el terrorismo» que quedarían, por tanto, excluidas de la libertad de expresión ${ }^{68}$.

${ }^{65}$ Sobre esta sentencia, vid. el análisis de Belavusau, U. (2010). «A Dernier Cri from Strasbourg: An Ever Formidable Challenge of Hate Speech (Soulas E Others v. France, Leroy v. France, Balsyte_Lideikiene_v. Lithuania)'». European Public Law, vol. 16, núm. 3, pp. 373-374, 376-377 y 382-389; y también Boyne, S. M. (2010), pp. 469-480.

66 Artículo 24.6 de la Ley de Prensa, de 29 de julio de 1881.

${ }^{67}$ CODEXTER (2008b). Freedom of expression and «apologie du terrorisme». Strasbourg: Council of Europe, p. 4, http://goo.gl/1hZYit, recuperado el 15.04.2014.

68 En el mismo documento el CODEXTER se refirió a la decisión de admisibilidad adoptada en el caso Kaptan c. Suiza, para afirmar que el TEDH parece estar preparado para excluir del 
El TEDH se refiere por primera vez ${ }^{69}$ al Convenio del Consejo de Europa (arts. 5 y 8) así como al Informe Explicativo que remite a los trabajos del CODEXTER sobre apología del terrorismo y considera que «el criterio seguido por los tribunales domésticos [condenando al demandante por complicidad con un delito de apología del terrorismo al «animar indirectamente al lector potencial a tener una opinión favorable al éxito de un delito criminal»] es compatible con el artículo 10 del Convenio» por cuanto «visto el conjunto con el texto que lo acompaña, la obra no critica el imperialismo americano, sino que apoya y glorifica su destrucción por medio de la violencia $^{70} \gg($ ap. 43).

$\mathrm{Y}$ es en este mismo fundamento jurídico donde la Corte hace otra afirmación relevante por cuanto «aprueba la opinión del Tribunal de apelación según la cual «las intenciones del demandante eran ajenas al proceso», remitiéndose al art. 8 de la Convención para la prevención del terrorismo para señalar que «la provocación no tiene por qué ir seguida necesariamente de efecto para constituir una infracción».

El análisis del Tribunal presta atención, en sus propias palabras, a «los términos empleados para ilustrar el dibujo y al contexto en el que se publicaron, teniendo asimismo en cuenta las circunstancias vinculadas a las dificultades relacionadas con la lucha antiterrorista» así como «el lenguaje inherente a la caricatura, que puede ser una forma de expresión artística, provocadora por definición», pero, en particular, valora esencialmente dos factores en relación con el contexto, además del carácter moderado de la multa impuesta: la «dimensión temporal» que debía haber llevado al demandante a actuar con mayor responsabilidad en el lenguaje utilizado (al publicarse la caricatura dos días después de los atentados del 11-S) y «el impacto de tal mensaje en una región políticamente sensible; pese a su carácter limitado debido a su publicación en el semanario en cuestión, el Tribunal constata sin embargo que ocasionó reacciones [...], que

ámbito de la libertad de expresión los discursos que defiendan y glorifiquen la violencia, pero en el caso en cuestión el Tribunal, pese a afirmar que «esta clase de discurso no está cubierta por el art. 10 del Convenio» (Fundamento de derecho 1), consideró que existía una injerencia justificada en la libertad de expresión [CODEXTER (2008b), págs. 5 y 6 ].

${ }^{69}$ Belavusau, U. (2010), pp. 376-377.

70 «El Tribunal se basa a este respecto en la leyenda que acompaña el dibujo y constata que el demandante expresa su apoyo y solidaridad moral con los presuntos autores, según él, del atentado de 11 de septiembre de 2001. A través de las palabras empleadas el demandante juzga favorablemente la violencia perpetrada contra miles de civiles y atenta contra la dignidad de las víctimas» (ap. 43). 
podían avivar la violencia y demostrando su impacto plausible en el orden público de la región» (aps. 38, 39 y 45).

La relevancia de esta sentencia es patente desde el momento en que el Relator Especial de las Naciones Unidas se remite a ella para justificar que su propuesta de definición del delito de incitación al terrorismo modifique la definición del art. 5 del Convenio sustituyendo la expresión «directamente» («... cuando ese comportamiento, ya preconice directamente o no la comisión de delitos terroristas...») por el término «expresamente» («... siempre que dicha conducta, propugne o no expresamente un delito de terrorismo...»), de tal forma que la incitación al terrorismo incluya también los casos en los que el efecto incitador derive tácitamente de formas de expresión que solo veladamente y mediante lenguaje simbólico o críptico manifiestan la aprobación de actos terroristas, como sucede en el caso de autos.

Desde el caso Leroy, el TEDH ha venido manteniendo los mismos principios generales en esta materia, sin perjuicio de la diversidad casuística que ha tenido que abordar. Como única novedad, cabe señalar que en la sentencia dictada recientemente en el caso Yavuz y Yaylali c. Turquía de 17 de diciembre de 2013 ha hecho mención expresa a la definición de la provocación pública al terrorismo contenida en el Convenio sobre la prevención del terrorismo ${ }^{71}$ (aps. 22-25) y a las pautas interpretativas del mismo dadas en el Informe Explicativo (ap. 26) mostrándose muy explícito al incluir en la incitación a la violencia conductas que no constituyen una apelación directa a la misma: «el Tribunal acepta que ciertas formas de identificación con una organización terrorista y, sobre todo, la glorificación de esta última pueden ser consideradas como un apoyo al terrorismo e incitación a la violencia y al odio. Del mismo modo, el Tribunal admite que la difusión de mensajes alabando al autor de un atentado, la denigración de las víctimas, las llamadas a financiar organizaciones terroristas u otros comportamientos similares podrían constituir actos de incitación a la violencia terroris$\mathrm{ta}^{72} \gg($ ap. 51).

${ }^{71}$ Con carácter previo, en el caso Herri Batasuna y Batasuna c. España de 30 de junio de 2009, el Tribunal hizo referencia, como argumento que justifica que la disolución de Herri Batasuna y Batasuna por el Tribunal Supremo español respondió a una «necesidad social imperiosa», al «deseo internacional de condenar la apología del terrorismo, tal y como lo atestigua en el plano europeo la Decisión Marco del Consejo de la Unión Europea sobre la lucha contra el terrorismo de 13 de junio de 2002 [...] y el Convenio del Consejo de Europa [...] que en su artículo 5 tipifica como delitos la "inducción pública a la comisión de delitos de terrorismo"» (ap. 90).

${ }^{72}$ Asume así la Corte de Estrasburgo la especificación de conductas constitutivas de incitación indirecta al terrorismo que tuvo en cuenta el CODEXTER al redactar la definición del art. 5 del 


\section{EL ENFOQUE NORTEAMERICANO: INMINENCIA Y PROBABILIDAD}

Las opiniones críticas con el modelo europeo de represión penal de la incitación al terrorismo han presentado siempre como contrapunto el enfoque norteamericano que condiciona la criminalización de la incitación a la intención de provocar una acción ilegal inminente y a la probabilidad de que tal acción sea cometida en las circunstancias dadas ${ }^{73}$.

La sentencia dictada por el Tribunal Supremo de los Estados Unidos en 1969 en el caso Brandenburg ${ }^{74}$ ha sido calificada como el ancla de la jurisprudencia norteamericana moderna sobre la libertad de expresión ${ }^{75}$. Según la misma, «las

Convenio núm. 196, haciendo suyas las sugerencias del Dictamen del Comisario de Derechos Humanos del Consejo de Europa (Explanatory Report, ap. 95).

73 Así, ya en las trece sentencias contra Turquía dictadas por el TEDH el 8 de julio de 1999 [Ceylan, Arslan, Gerger, Polat, Karatas, Erdogdu e Ince, Baskaya y Okçuoglu, Okçuoglu, Sürek y Özdemir, Sürek (núm. 1), Sürek (núm. 2), Sürek (núm. 3), y Sürek (núm. 4)] el voto particular concurrente formulado por el magistrado Bonello discrepó del criterio adoptado por la mayoría añadiendo la exigencia de que la incitación a la violencia sea tal que cree «un peligro manifiesto e inminente», citando literalmente varias sentencias del Tribunal Supremo norteamericano, entre ellas el caso Brandenburg y el caso Schenk.

Por otra parte, en la discusión acerca de la Decisión Marco de 2008 del Consejo de la Unión Europea, el caso Brandenburg fue alegado por la Comisión Internacional de Juristas como argumento para defender que la penalización de la incitación al terrorismo es desproporcionada y no responde a una necesidad social imperiosa si no incluye entre los elementos típicos un «riesgo inminente», o al menos, una aplicación e interpretación restrictiva del término «peligro» que requiera «un grado de inminencia en el peligro causado [INTERNATIONAL COMMISSION OF JURISTs (2008), p. 6].

${ }_{74}$ Brandenburg v. Obio 395 U. S. 444, 447 (1969).

75 Boyne, S. M. (2009). The criminalization of Speech in an Age of Terror, p. 4, http://ssrn. com/abstract $=1418496$, recuperado el 15.04.2014. Un resumen de la evolución de esta jurisprudencia en relación con la incitación a la violencia puede consultarse en WiLliams, A. F. «Prosecuting Internet Website Development Under the Material Support to Terrorism Statutes: Time to Fix What's Broken». De próxima publicación en New York University Journal of Legislation and Public Policy, pp. 15-25, http://ssrn.com/abstract=1018540, recuperado el 15.04.2014. Recientemente, se ha señalado que el Tribunal Supremo, al calificar los hechos enjuiciados en el caso Turner (2013) como amenazas y no como incitación, ha perdido la oportunidad de proporcionar orientación útil a otros tribunales sobre la forma de afrontar casos de incitación en Internet en los que la aplicación del estándar Brandenburg resulta incierta, especialmente por lo que se refiere al requisito de la inminencia [«First Amendment-Freedom of Speech-Second Circuit Affirms Threats Conviction in Internet Speech Case.-United States v. Turner, 720 F.3d 411 (2d Cir. 2013)». Harvard Law Review, vol. 127 (2014), pp. 2591-2592]. También sobre las dificultades de que la publicación de un mensaje en un sitio web pueda dar lugar a una acción ilegal inminente, Healy, M. A. (2009). «How the Legal Regimes of the European Union and the 
garantías constitucionales de la libertad de expresión y de la libertad de prensa no permiten a un Estado prohibir o proscribir la defensa del uso de la fuerza excepto cuando tal defensa esté dirigida a incitar o producir una inminente ilegalidad y sea probable que incite o produzca tal acción [.... \. Previamente, en otra sentencia el juez Holmes había establecido su conocido estándar del «peligro manifiesto e inminente ${ }^{76} »$ : «la cuestión en cada caso es si las palabras utilizadas son usadas en tales circunstancias y son de tal naturaleza que crean un peligro manifiesto e inminente de traer males sustanciales que el Congreso tiene derecho a prevenir. Es una cuestión de grado y proximidad ${ }^{77}$ ». En 1973 un nuevo pronunciamiento añadió al test Brandenburg que el discurso que incita debe tener un destinatario específico y determinado y que «la acción incitada debe ser inmediata y no diferida ${ }^{78}$ ».

Este «alto estándar para la protección de la libertad de expresión ${ }^{79}$ » establecido por el Tribunal Supremo interpretando la Primera Enmienda llevó a los Estados Unidos a formular una reserva al art. 20 PIDCP — que obliga a prohibir por ley «toda propaganda en favor de la guerra» $\mathrm{y}$ «toda apología del odio nacional, racial o religioso que constituya incitación a la discriminación, la hostilidad o la violencia»— para señalar que el mismo «no autoriza ni requiere legislación u otra acción de los Estados Unidos que pueda restringir los derechos a la libertad de expresión y asociación protegidos por la Constitución y las leyes de los Estados Unidos ${ }^{80} »$.

El contraste entre el enfoque europeo ya expuesto y el estándar norteamericano explica que la Resolución 1624 (2005) del Consejo de Seguridad de las

United States Approach Islamic Terrorist Web Sites: A Comparative Analysis». Tulane Law Review, vol. 84, pp. 190-192.

${ }^{76} \mathrm{Al}$ respecto, considerando también la invocación de este test en las decisiones del TEDH, Barnum, D. G. (2006). «The Clear and Present Danger Test in Anglo-American and European Law». San Diego International Law Journal, vol. 7, pp. 263-292.

77 Schenck v. United States, 249 U. S. 47 (1919).

${ }^{78}$ Hess v. Indiana, 414 U. S. 105 (1973).

79 OSCE OfFice for Democratic Institutions and Human Rights (ODIHR) (2006).

Background Paper on Human Rights Considerations in Combating Incitement to Terrorism and Related Offences. OSCE/CoE Expert Workshop «Preventing Terrorism: Fighting Incitement and Related Terrorist Activities», Vienna, 19-20 October 2006, p. 23.

${ }^{80}$ Asimismo, incorporaron también una declaración en virtud de la cual «para los Estados Unidos, el art. 5.2 que establece que los derechos fundamentales existentes en cualquier Estado parte no podrán ser menoscabados con el pretexto de que el Pacto los reconoce con menor extensión, tiene particular relevancia para el art. 19.3 que permitiría ciertas restricciones a la libertad de expresión. Los Estados Unidos declaran que continuarán adhiriéndose a las exigencias y mandatos de su Constitución con respecto a tales restricciones y limitaciones» (United Nations Treaty Collection, http://goo.gl/i5Jisn, recuperado el 23.04.2014). 
Naciones Unidas, adoptada a instancias del Reino Unido con el apoyo estadounidense, haya sido interpretada como un compromiso internacional de consenso, «un ambicioso intento de reducir las diferencias entre los enfoques europeo y americano sobre la prohibición de la incitación al terrorismo ${ }^{81}{ }$. Así, se ha dicho que ese espíritu de compromiso se pone de manifiesto, entre otros elementos, en que las referencias a la «glorificación (apologie)» del terrorismo no se incluyen en las disposiciones operativas de la Resolución sino tan solo en su Preámbulo para evitar discusiones terminológicas entre los Estados miembros, en el empleo del verbo «prohibir» en lugar de «penalizar» o «suprimir» usados en otras resoluciones relativas al terrorismo y, sobre todo, en el hecho de que se trate de una resolución sin fuerza vinculante a diferencia de la mayoría de las del Consejo de Seguridad que tratan sobre el terrorismo ${ }^{82}$.

Sin embargo, el propio informe de los Estados Unidos al Comité contra el Terrorismo sobre la implementación de la Resolución 1624 (2005), aunque declara que «nunca ha habido un caso en los Estados Unidos en el que la mera publicación de materiales escritos haya sido considerada como un delito de incitación punible» como consecuencia de las exigencias del estricto test Brandenburg, reconoce al mismo tiempo que «una serie de leyes estadounidenses penalizan conductas relacionadas con la expresión que apoya o fomenta actos de violencia, incluidos los actos de terrorismo (con independencia de que la ley en cuestión específicamente las caracterice como «incitación» o se refiera específicamente a «terrorismo» ${ }^{83}{ }$.

En este último sentido, se ha señalado que en el Derecho norteamericano el estándar Brandenburg convive de hecho con medidas legales que indirecta y colateralmente restringen la libertad de expresión ${ }^{84}$. Se cita al respecto, entre otras disposiciones, el delito de proporcionar a sabiendas «apoyo material» o «recursos» a una organización terrorista ${ }^{85}$. La aplicación de estas leyes ha dado lugar a procesos ampliamente comentados como son los casos $\operatorname{Rahman}^{86} \mathrm{y}$,

81 Barak-Erez, D. y Scharia, D. (2011), p. 20.

82 «La Resolución fue aceptada de esta manera como un compromiso y con el fin de permitir a los Estados Unidos apoyarla sin contradecir sus tradiciones constitucionales que niegan las restricciones a la libertad de expresión basadas en el contenido» (ibíd., pp. 21-22).

$83 \mathrm{~S} / 2006 / 397$. Response of the United States of America to the Counter-Terrorism Committee: United States implementation of Security Council Resolution 1624 (2005), pp. 4-5.

84 BAraK-Erez, D. y Scharia, D. (2011), p. 16

85 Ibíd., págs. 16-18, comentando los casos Rahman, Al-Timimi, e Iqbal; S/2006/397, pp. 5-8; y Renieris, E. M. (2009). «Combating Incitement to Terrorism on the Internet: Comparative Approaches in the United States and United Kingdom and the Need for an International Solution». Vanderbilt Journal of Entertainment and Technology Law, vol. 11, núm. 3, pp. 682-685.

86 United States $v$. Rabman, 189 F. 3d 88, 115-16 (2d Cir. 1999), comentada en RENIERIS, E. M. (2009), p. 684. 
especialmente, el caso Al-Hussayen ${ }^{87}$ en el que se juzgó al acusado por varios cargos de «apoyo material» al terrorismo mediante la creación y mantenimiento de páginas web. El delito de «apoyo material» al terrorismo fue creado por una ley de 1994 (arts. 2339A y 2339B del Título 18 del Código de Leyes de los Estados Unidos) pero fue la Patriot Act la que en 2001 incluyó en la definición de este concepto el «asesoramiento o asistencia experta ${ }^{88}$ », término que fue objeto de enmienda y aclaración en 2004 por la Intelligence Reform and Terrorist Prevention Act (IRTPA) que pasó a definirlo como «asesoramiento derivado de conocimiento científico, técnico u otro especializado»; pese a ello, en 2007 el Tribunal de Apelaciones del Noveno Circuito lo consideró «inadmisiblemente vago» porque la referencia genérica a «otro conocimiento especializado» cubría todos los supuestos imaginables extendiéndose al apoyo constitucionalmente protegido $^{89}$.

Tras este último pronunciamiento de 2007 se ha afirmado que las leyes sobre «apoyo material» al terrorismo no pueden ser usadas para perseguir acciones protegidas por la Primera Enmienda ${ }^{90}$ y que son particularmente inadecuadas para perseguir el apoyo o la incitación indirecta al terrorismo en Internet ${ }^{91}$. Pero en 2010 el Tribunal Supremo ha dictado una sentencia ${ }^{92}$ en la que considera que la prohibición penal del apoyo activo prestado en coordinación o bajo la dirección de una organización terrorista extranjera no es inconstitucional, aunque dicho apoyo se refiera a acciones y medios pacíficos y no violentos como proporcionar formación en Derecho Internacional Humanitario o derechos humanos, en tramitación de solicitudes de ayuda a organizaciones internacionales por catástrofes naturales o en negociaciones de paz. Queda así desechada la inconstitucionalidad del delito de proporcionar a sabiendas «apoyo material a una organización terrorista extranjera» y se acepta la limitación de la libertad de expresión como medida preventiva contra ataques terroristas cuya probabilidad de ocurrir se incrementa debido a tal apoyo ${ }^{93}$.

87 United States v. Al-Hussayen, case n. ${ }^{\circ}$ CR03-048-C-EJL, 2004 U. S. Dist. Lexis 29793, **1-3 (D. Idaho Apr. 6 2004). Vid. al respecto Boyne, S. M. (2009), pp. 11-16; Renieris, E. M. (2009), pp. 690-692; y Williams, A. F., pp. 1-14.

88 Williams, A. F., pp. 10-13.

89 Humanitarian Law Project v. Mukasey, 509 F. $3^{\text {rd }} 1122,1135-37$ (9 ${ }^{\text {th }}$ Cir. 2007); y ReNIERIS, E. M. (2009), pp. 694-695.

90 Renieris, E. M. (2009), p. 696

91 Williams, A. F., pp. 28-37.

92 Holder v. Humanitarian Law Project, 130 S. Ct. 2705 (2010).

93 Se argumenta que «tal apoyo libera otros recursos de la organización que pueden ser dirigidos a fines violentos. También ayuda relevantemente a la legitimación de grupos terroristas extranjeros - legitimación que hace más fácil para estos grupos pervivir, reclutar miembros y 
Con este planteamiento, el enfoque norteamericano no se aleja formalmente de la jurisprudencia clásica sobre la libertad de expresión por cuanto se afirma que la prohibición se abstiene de valorar el contenido de la expresión y se centra solo en la conexión entre el comunicante y una organización terrorista. Sin embargo, esta sentencia de 2010 tiene un efecto potencial de limitación de la libertad de expresión que va más lejos de las prohibiciones basadas en el contenido propias del modelo europeo al abrir la puerta a la prohibición de cualquier expresión relacionada con una organización terrorista, sin importar cuán pacífica pueda ser, desde el momento en que se considere llevada a cabo en coordinación o bajo la dirección de una organización terrorista ${ }^{94}$. Hay, pues, una vía americana, alternativa a la europea, que formalmente mantiene el enfoque tradicional de rechazar prohibiciones basadas en el contenido cuando el peligro no sea inminente y no criminaliza directamente la incitación al terrorismo pero que simultáneamente limita de forma indirecta la libertad de expresión en apoyo del terrorismo persiguiendo a quienes incitan al mismo utilizando delitos tipificados en términos muy generales y aparentemente neutrales desde el punto de vista del contenido de la expresión.

\section{CONCLUSIONES}

La Resolución 1624 (2005) del Consejo de Seguridad de las Naciones Unidas no define la incitación al terrorismo ${ }^{95}$ que insta a prohibir por ley a los Estados miembros, después de repudiar en su Preámbulo la apología; sin embargo, el Secretario General de las Naciones Unidas en 2008 declaró que solo la incitación al terrorismo —entendiendo por tal «un llamamiento directo a cometer actos terroristas con la intención de promover el terrorismo y en un contexto en el que ese llamamiento contribuya de manera directa a aumentar el riesgo real de que se cometa un acto terrorista»- puede prohibirse legalmente mientras que la

obtener fondos- todo lo cual facilita más ataques terroristas» [BARAK-EREZ, D. y SCHARIA, D. (2011), pp. 2-3 y 19].

${ }^{94} \mathrm{La}$ indefinición de los términos «en coordinación» o «bajo la dirección» utilizados por el Tribunal Supremo en el caso Holder v. Humanitarian Law Project no ha sido resuelta en un caso posterior de 2011 en el que el demandante fue condenado por «apoyo material» al terrorismo por haber traducido y difundido por Internet material de Al Qaeda. Vid. ABEL, N. (2013). «United States v. Mehanna, the First Amendment, and Material Support in the War On Terror». Boston College Law Review, vol. 54, pp. 711-750

95 Una crítica a esa ambigüedad y falta de claridad en SAUL, B. (2005). «Speaking of Terror: Criminalising Incitement to Violence». UNSW Law Journal, vol. 28, núm. 3, p. 870. 
apología no, excluyendo categóricamente la incitación indirecta ${ }^{96}$. El Convenio del Consejo de Europa contra el terrorismo, por el contrario, responde a la finalidad expresa de penalizar la incitación indirecta al terrorismo, tal y como resulta del Informe Explicativo y de la literalidad de su art. 5, dejando a la discrecionalidad de los Estados la criminalización de la apología entendiendo por tal la presentación de un delito terrorista como necesario y justificado.

Esta contradicción ha quedado amortiguada por la inclusión del art. 5 del Convenio entre las mejores prácticas de lucha contra el terrorismo por el Relator Especial de las Naciones Unidas que viene a sugerir que la incitación indirecta y no expresa al terrorismo puede ser penalizada mediante una descripción precisa que, al exigir la concurrencia de los requisitos de intención subjetiva y riesgo objetivo, supere la vaguedad de términos como «apología» o similares ${ }^{97}$.

Pero, dejando al margen la intencionalidad de la conducta sobre la que existe acuerdo ${ }^{98}$, el criterio de la conexión causal de la incitación con un riesgo o peligro de comisión de actos terroristas no termina de resolver el conflicto con la libertad de expresión. El grado de inminencia del peligro es una de las aristas de la cuestión: ¿en qué medida el peligro de acto terrorista debe estar próximo en el tiempo para que resulte justificado sancionar penalmente una expresión de apoyo verbal a la actividad terrorista? Especial problema se plantea cuando el proselitismo terrorista encubierto se lleva a cabo en un entorno docente en el que resulta difícil probar la relación causal del mensaje con los actos de unos pocos estudiantes realizados años después ${ }^{99}$.

La probabilidad del riesgo es otro de los aspectos polémicos a considerar. Frente a las opiniones, ya expuestas, que reclaman un juicio de probabilidad, el Convenio 196 se limita a exigir que la conducta provocadora «causes a danger» de comisión de delitos terroristas, esto es, no exige un grado cuantificable de proba-

96 A/63/337, de 28 de agosto de 2008. Informe del Secretario General. Protección de los derechos bumanos y las libertades fundamentales en la lucha contra el terrorismo, aps. 61 y 62, http://goo.gl/IdprIf, recuperado el 22.04.2014. Vid. también Ronen, Y. (2010), p. 23.

97 Vid. el apartado IV in fine. Pese a ello, publicaciones oficiales de las NU han seguido expresando, aunque menos categóricamente, la posición del Secretario General contraria a la penalización de la apología [Oficina del Alto Comisionado de las Naciones Unidas para los Derechos Humanos (2008). Los Derechos Humanos, el Terrorismo y la Lucha contra el Terrorismo. Folleto informativo n. 32 . Ginebra, pp. 45-46, http://goo.gl/K1ddTE, recuperado el 24.04.2014].

98 Aunque, como se ha señalado acertadamente, la exigencia de intención de incitar no ha sido directamente establecida como tal por el TEDH. A este respecto vid. HUNT, A. (2006), pp. 621-623.

99 Oficina de las Naciones Unidas contra la Droga y el Delito, Subdivisión de Prevención del Terrorismo (2006), p. 22. 
bilidad sino una mera valoración cualitativa de la posibilidad de que el peligro se produzca, con independencia de que se materialice o no. Se ha señalado que en este caso el verbo «causar» no se refiere a un efecto tangible y físicamente observable, sino a un peligro en potencia requiriendo un pronóstico judicial de un hecho futuro más que la constatación de una consecuencia ya ocurrida o existente ${ }^{100}$.

Aunque la jurisprudencia del TEDH se presenta como la base sobre la que se ha redactado la definición de la provocación pública al terrorismo del art. 5 del Convenio ${ }^{101}$, lo cierto es que la misma es ambigua acerca de la disyuntiva entre probabilidad o mera posibilidad del peligro de acto terrorista, remitiéndose a criterios como la naturaleza del autor y el destinatario del mensaje y, en especial, al contexto, para valorar si se causa o no tal peligro ${ }^{102}$. La posibilidad de que la aplicación de las leyes nacionales sobre incitación por los tribunales internos sea revisable jurisdiccionalmente por el Tribunal de Estrasburgo aplicando criterios jurisprudenciales asentados se puede considerar como una fortaleza del enfoque europeo al contrapesar en favor de la libertad de expresión las prohibiciones penales de expresar opiniones de apoyo al terrorismo. Pero si se analiza la multiplicidad casuística de decisiones del Tribunal al valorar los elementos contextuales y circunstanciales de cada caso, esta ventaja se relativiza en la medida en que el ámbito de discrecionalidad jurisdiccional sigue siendo amplísimo. El problema no es la inexistencia de criterios jurisprudenciales prefijados sino su aplicación a situaciones fácticas tan multiformes que en su diversidad de matices se desvanecen en un grado considerable las pretensiones de certeza y predictibilidad de los pronunciamientos.

Lo dicho pone de manifiesto la extraordinaria relevancia del rol de los órganos jurisdiccionales que pueden ampliar o estrechar el ámbito real de las prohibiciones penales de la incitación más allá de las decisiones normativas subyacentes, desde el momento en que la ambigüedad e indefinición de las disposiciones legales convierte en crucial la valoración del contexto ${ }^{103}$ y ello tanto en la experiencia americana como en la práctica europea ${ }^{104}$.

En febrero de 2013 un think-tank israelí ha promovido un proyecto de convenio internacional para la prevención de la incitación al terrorismo con objeto de presentarlo al Secretario General de las Naciones Unidas. Dicho proyecto

${ }^{100}$ Ibid., p. 23

101 CODEXTER (2004) 34, cit., p. 4.

102 Ronen, Y. (2010), p. 28; Hunt, A. (2006), pp. 619-621; y Boyne, S. M. (2010), pp. 441-446.

103 Barak-Erez, D. y Scharia, D. (2011), p. 24.

${ }^{104}$ CM (2006) 204 revised, de 28 de noviembre de 2006. Joint OSCE-Council of Europe Expert Workshop on Preventing Terrorism: Fighting Incitement and Related Terrorist Activities (Vienna, 19-20 October 2006), http://goo.gl/kurwpC, recuperado el 23.04.2014. 
especifica que tanto la incitación directa como la indirecta al terrorismo tendrán la consideración de crímenes internacionales y define la incitación en términos similares al Convenio 196 incluyendo en la misma la denigración o menosprecio de un grupo para provocar terror o violencia contra el mismo ${ }^{105}$.

Desde una perspectiva académica se ha criticado que dicho proyecto pretenda extender universalmente el estándar europeo que solo exige que la incitación pueda causar un peligro de comisión de acto terrorista. Se argumenta que en la medida que el proyecto o criminaliza la incitación indirecta en términos incluso más amplios que el Convenio de 2005 y la Decisión Marco de la UE — por cuanto se refiere no solo a delitos de terrorismo tipificados sino a «actos de terror»o «violencia» contra personas o grupos nacionales, étnicos o religiosos_- debe incluir un umbral de probabilidad del daño más elevado, en línea con las directrices que dio el Secretario General de las NU en $2008^{106}$, para evitar que los Estados puedan utilizarlo como cobertura a fin de silenciar la disidencia legítima. Así, se dice que los instrumentos europeos reflejan un consenso interno que, por una parte, difícilmente será aceptado por los Estados Unidos al penalizar la incitación indirecta y que, por otra parte, no es apropiado extrapolarlo universalmente sin tener en cuenta que ha surgido entre Estados cuya legislación está sujeta al riguroso control jurisdiccional del TEDH mientras que no existe ningún mecanismo internacional de control de posibles abusos contra la libertad de expresión al amparo de la Resolución $1624(2005)^{107}$.

Title:

INCITEMENT TO TERRORISM AND FREEDOM OF EXPRESSION: THE INTERNATIONAL FRAMEWORK OF A PROBLEMATIC RELATIONSHIP

105 Draft International Convention for the Prevention of Incitement to Terror, redactado por el diplomático israelí A. BAKER y presentado en la «Conference on Incitement to Terror and Violence - New Challenges, New Responses», Nueva York, 28 de febrero de 2013, art. 1, http://goo.gl/bWb0vj, recuperado el 24.04.2014.

106 «Que [...][el] llamamiento contribuya de manera directa a aumentar el riesgo real de que se cometa un acto terrorista» $y$ «que [las expresiones] probablemente resulten en su efectiva comisión» (A/63/337, aps. 61 y 62).

107 Ronen, Y. (2012). «Incitement to Terrorism in International Law», en BAKER, A. (ed.) (2012). The Changing Forms of Incitement to Terror and Violence: The Need for a New International Response. Jerusalem Center for Public Affairs and the Konrad-Adenauer-Stiftung, p. 144; y Ronen, Y. (2010), pp. 24, 29 y 31. 


\section{Summary:}

I. Approach to the topic. The indefiniteness of the incitement to terrorism within the United Nations system. II. Public provocation to terrorism in Council of Europe Convention N. ${ }^{\circ} 196$ : the deliberate inclusion of indirect incitement. III. The case-law of the Strasbourg Court as interpretative parameter of the Convention. IV. Criticisms of the European model of criminalization of incitement to terrorism. V. Subsequent ECtHR case-law developments. The Leroy and Yavuz and Yayali cases. VI. The US approach: imminence and likelihood. VII. Conclusions.

\section{Resumen:}

La Resolución 1624 (2005) del Consejo de Seguridad de las Naciones Unidas no define la incitación al terrorismo. Sí lo hace, por el contrario, el Convenio núm. 196 del Consejo de Europa de 2005 que caracteriza la provocación pública al terrorismo incluyendo deliberadamente la incitación indirecta, exigiendo una intencionalidad específica y un resultado de peligro de comisión de un delito terrorista. El Informe explicativo del Convenio remite a la jurisprudencia del TEDH para establecer los elementos a considerar en la apreciación de dicho peligro haciendo así de ella un parámetro interpretativo. La Decisión Marco del Consejo de la Unión Europea ha adoptado desde 2008 la misma definición que el Convenio por lo que cabe hablar de un modelo europeo de penalización de la incitación al terrorismo que ha sido criticado por utilizar un definición abierta y general en conflicto con el principio de seguridad jurídica y por la indeterminación de la naturaleza del peligro provocado por la incitación. Estas críticas no han impedido, sin embargo, que el Relator Especial de las Naciones Unidas haya considerado la definición del Convenio como una práctica óptima en la lucha contra el terrorismo. Con posterioridad al Convenio, el TEDH ha dado lugar a desarrollos jurisprudenciales relevantes sobre la incitación indirecta como los casos Leroy (2008) y Yavuz y Yayali (2013). El enfoque norteamericano que requiere inminencia y probabilidad del peligro es el referente de las posiciones críticas con el estándar europeo que se pretende extender universalmente en un proyecto de convenio internacional para la prevención de la incitación al terrorismo surgiendo la problemática de su adecuación más allá del contexto europeo en el que ha surgido.

\section{Abstract:}

Resolution 1624 (2005) of the Security Council of the United Nations does not define incitement to terrorism. By contrast, Council 
of Europe Convention n. ${ }^{\circ} 196$ on the Prevention of Terrorism (2005) characterizes public provocation to terrorism deliberately including indirect incitement and requiring both specific intent and a result of danger of commission of a terrorist offense. The Explanatory Report of the Convention refers to the case-law of the ECtHR to fix on the elements to be considered in the assessment of the danger, thus making it an interpretative parameter. The Framework Decision of the Council of the European Union has adopted since 2008 the same definition that the Convention as it is possible to speak of a European model of criminalization of incitement to terrorism that has been criticized for using a broad and open definition in conflict with the principle of legal certainty and not determining the nature of the danger caused by incitement. These criticisms have not prevented, however, that the Special Rapporteur of the United Nations has considered the definition of the Convention as a best practice in the fight against terrorism. After the Convention, the ECtHR has led to relevant developments of case-law on the indirect incitement as cases Leroy (2008) and Yavuz and Yayali (2013). The US approach that requires imminence and likelihood of danger is the benchmark for the critical positions with the European standard that is intended to extend universally in a draft international convention for the prevention of incitement to terror raising the issue if it is appropriate beyond the European context in which it has emerged.

Palabras clave:

Terrorismo, incitación, apología, libertad de expresión.

Key words:

Terrorism, incitement, glorification, freedom of expression. 